\title{
O jornalista gastronômico e a arte de julgar**
}

Márcia Atálla Pietroluongo **

RESUMO: Análise do julgamento de gosto e das imagens de jornalista produzidas nas revistas gastronômicas Saveirs, GaultMillau, La Bonne Cuisine e Cuisine et Vins de France, à luz da análise semiolinguiistica do discurso de Patrick Charaudeau e de conceitos sociológicos de Pierre Bourdieu.

Desde a Antigüidade Clássica, a arte de argumentar suscita enorme interesse e atenção por parte dos estudiosos, na medida em que seu domínio permite ao locutor-emissor exercer uma maior influência sobre o interlocutor-receptor. A eficácia do locutor advém de sua capacidade de persuadir e de seduzir o Outro, fazendo-o aderir a suas opiniões. A argumentação se fundamenta, então, num processo de co-enunciação e se baseia num raciocínio construído em proposições sobre o mundo.'

No campo da Gastronomia, tal como se pode observar nos textos das revistas francesas Saveurs, GaultMillau, La Bonne Cuisine e

* Recebido para publicação em abril de 1999.

** Professora do Setor de Letras Francesas da Universidade Federal do Rio de Janeiro.

'A terminologia, aqui empregada, é aquela da análise semiolingüistica do discurso de Patrick Charaudeau. Por ausência de espaço e por considerar que o enfoque teórico adotado é de amplo conhecimento dos leitores desta revista, optei por centrar-me na análise do tema em questão. 
Cuisine et Vins de France, todo o discurso do jornalista é orientado no sentido do êxito de suas finalidades discursivas: instruir/informar, seduzir e legiferar. Para a consecução dessas finalidades, o crítico lança mão de algumas estratégias que serão analisadas neste artigo.

O Contrato de comunicação desse discurso pode ser ilustrado pela carta-despedida do jornalista Christian Millau, onde este faz um balanço de seus 45 anos de jornalismo, 25 dos quais dedicados à GaultMillau. Esse balanço demonstra claramente algumas de suas finalidades, alcançadas com êxito:

Le sentiment d'avoir fait bouger la cuisine, donné aux chefs la place qu'ils méritaient, tiré de l'ombre tant de talents encore inconnus ou méconnus, ouvert le jeune à de grandes ambitions, aiguisé l'appétit du public et contribué ainsi à la formidable explosion du goût qui modifia, en profondeur, le paysage alimentaire dans les années 70 ? Oui, je crois sincèrement que nous avons fait là du bon travail. La révolution de la "nouvelle cuisine", de la cuisine créative qui fit le tour du monde et, après laquelle, quelles qu'en fussent les erreurs d'interprétation ou les mauvaises copies, plus rien ne fut comme avant, ni pour les cuisiniers ni pour les consommateurs? Et parallèlement la remise à l'honneur d'un terroir authentique qui en était la nécessaire contrepartie? De cela non plus, il n'y a pas lieu de rougir. (GM $\mathrm{n}^{\circ} 302$, Merci pour tout, p.3).

Dessa carta se depreendem as funções e responsabilidades do iornalista gastronômico:

1. formar opinião;

2. influenciar as maneiras, formando o gosto do público;

3. revolucionar o mundo culinário, influenciando os hábitos de consumo;

4. respaldar o talento dos chefs;

5. avaliar e guiar competentemente, determinando o bom e o ruim, o belo e o não-belo nesse campo do saber;

6. descobrir e testar as novidades gastronômicas, do produto ao prato.

7. revalorizar uma tradição regional esquecida.

Ao longo dos diversos textos, o jornalista orienta seu discurso na tentativa de monitorar o leitor, implantando seu sistema axiológico, 
através de opiniões, constatações, apreciações, máximas. A configuração semântica da argumentação gastronômica é, pois, estabelecida através da atribuição de valores pertinentes a vários domínios de avaliação²:

1. O domínio da Ética, baseado nos conceitos de bom ou ruim:

A ética culinária francesa contemporânea se fundamenta em três traços constitutivos obrigatórios: a qualidade e o frescor do produto, a precisão do cozimento e o valor do condimento, aos quais se opõem os valores inversos: a ausência de qualidade e/ou frescor do produto, a imprecisão do cozimento e o desequilíbrio (diminutivo ou excessivo) do condimento.

(...) on reconnaît dans cette agilité à bien traiter le produit, la marque d'une grande école. ( $\mathrm{S} \mathrm{n}^{\circ} 43$, Actualités, A Table, p.6).

Grâce à quelques épices astucieuses, parfaitement dosées, ce seigneur des mers s'enflammera sous sa royale carapace et livrera ses saveurs. (CVF $\mathrm{n}^{\circ} 12$, Recette simple d'un chef, p.80)

(...) c'est surtout dans l'accord des arômes et la perfection des sauces parfumées que s'exprime son talent. Il modère l'usage de la crème, des fonds épais, du beurre, il leur préfêre l'huile d'olive, les jus, les sucs plus digestes et savoureux. Sortir de table léger mais nourri, telle est l'intention qui préside à sa cuisine, sans sombrer dans l'excès diététique; ce qui n'interdit ni quelque sauce au vin, ni quelque tartelette. (BC $n^{\circ} 123$, Secret du chef, p.42)

M. Chen, le chef, (...) cuisine avec beaucoup de finesse (les cuissons, notamment sont remarquables). (GM n³03, Tables Paris, p.106)

2. O dominio da Verdade, fundamentado nas noções de verdadeiro ou falso:

Voilà une vraie cuisine rustique et raffinée, chic sans chichis, alerte et lyrique, au sens aigu des nuances et des contrastes dans un cheminement de saveurs cultivées et sagaces. ( $\mathrm{S} \mathrm{n}^{\circ} 44$, Actualités, A Table, p.8)

2 recorte dos procedimentos semânticos utilizados bascia-se na proposta que faz Charaudeau (1992: 814, $815)$ para o que chama de mise en argumentation. 
A La Timonerie, son restaurant, il sert une incomparable paella aux gambas et travers de porc qui retrouve chez lui ses vraies valeurs. (CVF $\mathrm{n}^{\circ} 14$, Recette simple d'un chef, p.84)

Nas duas citações seguintes, o tom firme das opiniões do jornalista gastronômico imprime a esses enunciados um valor de verdade:

Le danger de l'authentique, c'est la fermeture. Parce qu'il conduit à l'appauvrissement des formes, de même que la tradition conduit à la sieste des consciences quand on fait uniquement appel à elle. On glisse vite fait de l'authentique au typique, puis du typique au cliché. (GM n³00, Alsace gourmande, p.41)

C'est souvent à travers l'art que transparait le mieux la réalité. (GM $\mathrm{n}^{0} 304$, Bretagne maritime, p.34)

Para a ética culinária em voga é imprescindível trabalhar na confluência entre o gosto original do produto e os sabores que the são associados para exaltá-lo. Isso porque o que está em jogo é nada menos do que o "verdadeiro gosto das coisas", como se pode constatar nos dois fragmentos abaixo:

Mais c'est surtout une grande réussite gourmande, presqu'émouvante, parce qu'elle nous restitue, magnifié par la patte d'un grand chef, le vrai goût des choses. (BC n 124, Secret du chef, p.44)

(...) le chef propose à une clientèle de passage et aux industriels de la région de partir en sa compagnie à la recherche du "vrai goût des choses". (GM n³01, Tables province, p.16)

O discurso gastronômico francês contemporâneo, nas revistas pesquisadas, é salpicado de textos que registram a tendência a um certo platonismo, ou seja, uma certa ótica que recupera alguns traços da filosofia platônica. Assim, os ideais de Verdade e Beleza estão intrinsecamente ligados à idéia do Bem, ao Mundo das Essências.

3. O domínio da Estética, definido em termos de belo e feio:

Há na cultura francesa um consenso social quanto ao valor artísitico da obra culinária. Consenso que se estabelece entre um chef 
que deposita em sua Obra uma intenção estética e o sujeito-degustador que a apreende como tal.

Ou ce chef-d'oeuvre absolu que Solivérès accomplit avec le petit épeautre de Bernadette Liardet à Sault dans un sublime "risotto d'épeautre en sotl'y-laisse de poularde, crête et rognons de coq mijotés (mais aussi aux cèpes d'Auvergne)". (S n 44, Actualités, A Table, p.8)".

le divin brochet meunière (GM n 303 , Recettes, p.56)

parfait foie gras de canard dans sa fine gelée ( $\left(\mathrm{S}^{\circ} 43\right.$, Actualités, A Table, p.10)

harmonieuse composition de pommes de terre de Noirmoutier aux fruits de mer $\left(\mathrm{GM} \mathrm{n}^{\circ} 300\right.$, Tables province, p.20)

merveilleux homard au miel et au piment (GM n²99, Tables Paris et Région parisienne, p.186)

la magnifique barbue pochée sur l'arête ( $\mathrm{S} n^{\circ} 43$, Actualilés, $A$ Table, p.10) les splendides galettes de Saint-Jacques aux cèpes ( $\mathrm{S} \mathrm{n}^{\circ} 45$, Actualités, A Table, p.100)

beau turbot au jus de viande $\left(\mathrm{GM} \mathrm{n}^{\circ} 300\right.$, Tables province, p.20)

O ideal de cozinha francesa atual busca atingir algumas qualidades, positivando não apenas o belo e o sublime, mas também o delicioso, o original, o inteligente, o sensual, o leve, o simples refinado, o rico, que, entre outros, se organizam em diversos campos semânticos.

Nunca é demais lembrar que esses qualificativos, aos quais se opõem seus respectivos antônimos, fazem parte do léxico da ética e da estética burguesas. $\mathrm{O}$ universo discursivo do julgamento de gosto fundamenta-se em certos clichês, sedimentados lexicalmente:

Com efeito, todos os agentes de uma determinada formação social têm em comum um conjunto de esquemas de percepção fundamentais que recebem um começo de objetivação nos casais de adjetivos antagonistas freqüentemente empregados para classificar e qualificar as pessoas ou os objetos nos campos mais diferentes da prática. Matriz de todos os lugares comuns que só se impõem tão facilmente graças à adesão de toda a ordem social, a rede das oposições entre alto (ou sublime, elevado, puro) e baixo (ou vulgar, sem graça, modesto), espiritual e material, fino (ou refinado, elegante) e grosseiro (ou gordo, gorduroso, bruto, brutal, rude), leve (ou sutil, vivo, habilidoso) e pesado (ou lento, espesso, obtuso, laborioso, de- 
sajeitado), livre e forçado, largo e estreito ou, numa outra dimensão, entre único (ou raro, diferente, distinto, exclusivo, excepcional, singular, extraordinário) e comum (ou ordinário, banal, trivial, qualquer), brilhante (ou inteligente) e opaco (ou obscuro, apagado, mediocre) tem por princípio a oposição entre a "elite" dos dominantes e a "massa" dos dominados (...). (BOURDIEU, 1979:546)

4. O dominio do Hedônico, definido em termos de agradável e desagradável, sobretudo enfatizando os valores dos sentidos e do prazer:

salade plutôt agréable et croquante $\left(\mathrm{GM} \mathrm{n}^{\circ} 303\right.$, Tables province, p. 106)

Le métier de cuisinier qu'il [Joël Robuchon] exerce non par vocation, mais par choix, "car il fait appel aux cinq sens et doit les satisfaire", le passionne. L'homme est exigeant. Et même au sommet de son art, il brille d'un désir toujours vif de faire encore mieux pour prodiguer encore plus de plaisir. (...) (GM n' 302, Recettes, p. 97)

Un plat tendre et fin. Une chapelure d'herbes croustillantes enveloppait la chair fondante, rose et bien parfumée de la viande. Un coulis de tomates fraiches, rehaussé d'une réduction légère au vinaigre balsamique et de minuscules girolles sautées l'accompagnaient. Doux moment! Et qu'il illustrait bien le talent et la cuisine de Gérard Boyer, une cuisine à la fois simple, intelligente et sensuelle. (BC $\mathrm{n}^{\circ} 125$, Secret du chef, $\mathrm{p} .40$ )

Déguster la chair fumante et nacrée du poisson entre la panure croustillante et la peau fondante est $u$ in enchantement (...). (GM $n^{\circ} 302$, Recettes, p. 98)

Nos dois últimos exemplos, os mesmos contrastes se efetuam: herbes 'croustillantes'/ chair 'fondante' e panure 'croustillante'/ peau 'fondante'. O croustillant (que estala sob os dentes) no exterior e o fondant (que derrete) no interior. A substantivação e adjetivação são propostas no sentido de provocar no leitor, ao imaginar o prato descrito, um efeito cenestésico resultante da difusão de sensações internas orgânicas e psíquicas que atingem todos os sentidos, promovendo um sensual bem-estar.

O caráter hedônico da arte gastronômica é constantemente ressaltado. Esta tem a particularidade de só poder ser alcançada através da fusão sinestésica integral, onde todos os sentidos são mobilizados simultaneamente na experiência estética da degustação do pratoobra. 
5. O domínio do Pragmático, calcado nos valores de utilidade e inutilidade:

Il ferait mietux, en revanche, de renoncer aux langoustines au coulis de cresson, faute de pouvoir s'offrir un produit de qualité suffisante. (GM n³04, Tables Paris et Région parisienne, p.112)

Il lui faudra cependant ajuster ces cuissons: cocos un peu fermes, agneau un brin juste. (GM n $\mathrm{n}^{\circ} 301$, Tables province, p.15)

As injunções "Il ferait mieux" e "Il lui faudra cependant" funcionam como "seria mais útil" ou "seria melhor". No campo do discurso gastronômico, o domínio pragmático está freqüentemente associado aos domínios ético e estético, uma vez que o útil, na tradição perpetuada por Platão, ainda muito presente no imaginário desse discurso, está indissoluvelmente ligado ao Bem e ao Bom.

Aos ideais dos jornalistas somam-se os valores de mundo dos próprios chefs e de personagens importantes nesse campo do saber. Tais valores corroboram integralmente os domínios de avaliação propostos pelos jornalistas. A título de exemplo, uma citação do chef Jacques Puisais, do Instituto do Gosto de Tours, que vem reforçar a axiologia do fazer-saber gastronômico:

Le goût, ce sont les sens associés, une émotion presque sauvage, la première expression de la vie. Quelqu'un qui ne saurait définir un aliment que par "bon" ou "mauvais" est un handicapé. Et un aliment possède son langage.

On doit pouvoir s'exprimer s'il est moelleux, craquant, onctueux, salé, iodé... (S n 45, Flânerie (Tours Gourmand), p.45)

Nessa citação, o gosto passa da necessidade primeira, caracterizada pela faculdade de percepção dos sabores, à possibilidade de distinção fundamental que traz a capacidade de transformar essa percepção num julgamento estético. ${ }^{3}$ Este, longe de se bastar nos con-

${ }^{3}$ O emprego do vocábulo gosto no âmbito artístico é revelador de un deslocamento semântico operado, partindo do alimentar para o artistico. Em seu Dicionário Filosófico (1764), Voltaire constata que: "O gosto, esse sentido, esse dom de discernir nossos alimentos, produziu em todas as linguas conhecidas a metáfora que exprime, pela palavra gosto, o sentimento das belezas e dos defeitos em todas as artes: trata* se de um discernimento imediato, como o da lingua e do palato, antecedendo toda reflexão; como o primeiro, ele é sensivel e voluptuoso para com o bom, rejeitando enfaticamente o ruim." 
ceitos de 'bom'e 'ruim', deve ser enriquecido pela gama de adjetivos (macio, crocante, untuoso, salgado, iodado, etc) oferecidos pelo universo semântico do campo culinário-gastronômico.

O sujeito-degustador deve adjetivar o alimento com o conhecimento de causa que lhe é dado pela freqüentação do refinado ambiente da gastronomia francesa. A impossibilidade, por um dado sujeito, de opinar, de escolher o 'bom', o 'ruim' e suas propriedades correlatas dentre as possibilidades estilísticas oferecidas por seu espaço social, o alijaria definitivamente de seu grupo, pois o gosto é justamente aquilo que permite que os indivíduos, participantes das mesmas práticas, se orientem "naturalmente" em direção ao(s) lugar (es) que lhes são determinados (BOURDIEU, 1979:544). As escolhas estéticas se inserem, assim, no âmbito das escolhas éticas constitutivas do estilo de vida de cada formação social. (BOURDIEU, 1979:322)

Aqui, cabe perfeitamente o aforismo do gastrônomo BrillatSavarin (1965:23), segundo o qual "os animais pastam; o homem come; só o homem de espírito sabe comer". E sobretudo discorrer sobre a arte de comer, papel para os críticos gastronômicos e para os chefs de cozinha.

Para o jornalista gastronômico, a informação tem que ser um veículo de prazer, capaz de suscitar emoções e desejos no leitor. A matéria apresentada deve funcionar como um espaço de atração no qual a imaginação e as inclinações do leitor vão se projetar. Logo, é preciso que esse espaço seja tão saboroso quanto os pratos e receitas descritos.

No âmbito da gastronomia, informar e seduzir estão intimamente ligados, na medida em que todo o fazer do crítico está a serviço de um dizer que, ao apreciar, julgar e avaliar, revela a sua própria "subjetividade". A imagem de crítico proposta é a de alguém que, ao

\footnotetext{
"Trata-se aqui evidentemente de um efeito de subjetividade. Reproduz-se a ilusão de uma "pessoa integral", fonte de um sentido ancorado num dado tempo e num dado espaço. Tal "subjetividade" está na verdade na base de uma formą̧ão disctursiva que normatiza o espaço da avaliação-critica gastronônica.
} 
transmitir suas paixões e prazeres, procura sensibilizar o leitor, fazêlo vibrar, incitá-lo a degustar.

A incitação à degustação e ao prazer dela proveniente passa, assim, pela figura do crítico que ocupa o lugar de um intermediário entre o chef e o leitor. Para tal, o jornalista se imbui do intuito de servir de guia ao leitor, dando-lhe as chaves que abrirão portas, fazendo-o compreender os meandros do fazer-prazer gastronômico, desvelando o não-aparente, iluminando e celebrando o ato criador do chef retratado.

O comportamento enunciativo predominante do jornalista das revistas pesquisadas é o de enunciador-crítico-avaliador. No entanto, há diferenças de perspectiva na figura de avaliador nas diferentes revistas. É fundamental ressaltar que embora esse enunciador-crítico-avaliador esteja presente em todas as revistas pesquisadas, ele não ocupa o mesmo espaço em todas elas. Em GaultMillau, seguido de Saveurs, a prevalência da crítica gastronômica coloca-o em relevo de forma maciça, o que não se pode dizer de Cuisine et Vins de France e La Bonne Cuisine, centradas sobretudo em apreciações positivas, relativas aos chefs de cozinha retratados.

O locutor-enunciador-jornalista como critico-avaliador faz apreciações sobre todos os aspectos que concernem a Gastronomia, da decoração à recepção do restaurante, da qualidade dos produtos ao resultado da cozinha:

\section{Le Pò̀te}

Le décor assez vieillot n'inspire déjà pas un sonnet, ni même un quatrain. Comme par hasard, il manque les plats dont nous avions le plus envie et, si la carte se veul lyrique, aucune envolée n'est à signaler; malgré des soupçons d'originalité (...) Le seul intérêt est sans doute le prix du menucarte: pour $135 \mathrm{~F}$, il propose par exemple des pétoncles à la ratatouille froide, une morue fraîche (trop cuite) au citron vert et au pain perdu ( $p l u t o t$ bon) aux fruits de saison. Est-ce bien le même Antoine Gayet que nous avons connu avec deux toques au Monarque de la Défense? $\left(\mathrm{GM}^{\circ} 300\right.$, Tables Paris et Région parisienne, p.109) 
É comum em todas as revistas pesquisadas a postura de um critico que se dirige ao leilor, através do pronome pessoal vous ou do imperativo, incitando-o a consumir:

Alors! N'hésitez plus; risquez-vous à cette étonnante terrine d'agrumes. (CVF $n^{\circ} 11$, Recette simple d'un chef, p.106)

Gageons que vous aussi, en essayant les diverses recettes de cet esprit fécond, vous atrez envie d'aller goûter sur place sa cuisine. (BC $n^{\circ} 120$, Secret du chef, p.36)

Si un jour le spleen vous prend, que le goût de la vie vous paraît manquer de sel, allez passer un week-end chez Jean et Sophie Bardet à Tours. Et si vous êtes en pleine forme, ce n'est pas une raison pour vous priver. ( $S n^{\circ} 45$, Vins, Les Portos, une passion des chefs, p.84)

Patrick Charaudeau $(1988: 67,68)$ faz uma distinção entre o enunciador-avaliador e o enunciador-crítico. O primeiro faz apreciações de ordem afetiva que englobam os valores ético, estético, hedônico e pragmático e apreciações de ordem cognitiva apoiadas em suas opiniões, conviç̧ões, suposições e certezas. O segundo se manifesta através da competência de seu saber que abrange não somente seus conhecimentos técnicos, mas também o conhecimento da biografia dos implicados, da história e curiosidades do gênero descrito e de seus personagens mais importantes, citando e comentando as declarações destes. No discurso gastronômico, em particular, o enunciador-crítico é assimilado ao enunciador-avaliador.

Em alguns casos, o enunciador-avaliador se apresenta antes de tudo como um degustador arquetípico, numa relação de cumplicidade com a figura do leitor-degustador:

(...) il se passe toujours quelque chose de nouveau dans l'assiette avec la cuisine inventive, maline et légérissime de Patrick Cirotte, voici assurément l'une des adresses où nous aimons revenir à titre personnel. Dans la chaleur de l'été, combien était agréable la fraicheur d'une émulsion de tomates et melon à l'aneth, d'une araignée de mer décortiquée sur son lit de céléri remoulade (...) Pour cette rentrée, nous aurons peut-être droit au retour de l'effiloché de queue de boeuf au radis noir et à la moelle (...) (GM nº300, Tables Paris et Région parisienne, p.108) 
(...) dès l'ouverture (...) nous sommes tombés sous le charme d'une gelée de chasse absolument exquise avec ses légumes potagers et une légère vinaigrette au jus de gibier (influence Chapel), une non moins délicieuse salade aux herbes fraîches, vieux parmesan et cèpes en copeaux (...) d'une longe de veau de lait en cocotte, girolles et persil plat, à fondre d'émotion. $\left(\mathrm{GM} \mathrm{n}^{\circ} 302\right.$, Tables province, p.139)

A presença do pronome "nous" dá um cunho "afetivo" aos dois relatos, fazendo crer que não se trata somente de um profissional cumprindo seu dever de visita aos restaurantes mencionados, mas de uma pessoa integral, desfrutando do prazer de saborear a cozinha que lhe é oferecida, o que reforça mais uma vez o caráter idealista de enunciador proposto. (cf. nota 4)

O primeiro exemplo se mostra um misto de afetividade e apreciação, afetivo quando afirma sua "subjetividade" em "voici assurément l'une des adresses où nous aimons revenir à titre personnel", apreciador em "cuisine inventive, maline et légérissime" ou ainda em "combien il était agréable la fraîcheur d' une émulsion de tomates...", o adjetivo agréable dando um valor afetivo à apreciação. $\mathrm{O}$ fragmento nous aurons peut-être droit au retour insiste talvez na cumplicidade com o leitor: Nous aqui é um mero plural de modéstia ou incluiria o leitor? O segundo exemplo marca toda a "emoção" do sujeito enunciador: "nous sommes tombés sous le charme", "à fondre d'émotion", com a contribuição de advérbios e adjetivos: gelée de chasse "absolument exquise"; une "non moins délicieuse" salade.

O enunciador-avaliador se apresenta também como um freqüentador típico, duplo do leitor:

Une table simple et honnête comme on aimerait en rencontrer le plus souvent sur le bord de nos routes. (GM n³04, Tables province, p.21)

Un bistrot de quartier comme tant de Parisiens aimeraient en trouver à leur porte: atmosphère détendue fleurant presque la province, prix serrés et sans surprise (...), et nourritures simples mais distrayantes, sachant ne jamais sombrer dans le sempiternel ni le convenu (...) (GM n 304 , Tables Paris et Région parisienne, p.112)

Il nous arrive comme cela de quitter un restaurant en songeant: un jour; nous pourrons dire que nous avons été les premiers à en parler: Allons, 
restons modestes, cette petite maison de village a déjà tapé dans l'oeil du bon peuple d'Ampuis (...) (GM $\mathrm{n}^{\circ} 301$, Tables province, $\left.\mathrm{p}, 14\right)$

Nesse caso, os pronomes on, nous são utilizados com a estratégia de forjar a ficção de um consenso, onde crítico e público dividiriam os mesmos pontos de vista quanto aos lugares freqüentados.

Eventualmente, o enunciador-crítico tece comentários e opiniões sobre seu ofício, funcionando como um metacrítico:

Les Lyonnais viennent ici le dimanche, ce qui n'est pas rien, curieux qu'ils sont de découvrir à leur porte l'impertinent talent que Maximin a su communiquer à son poulain. La Clé D'Or donc pour Philippe Gauvreau, jeune chefde qualité, remarquablement inspiré par un des meilleurs cuisiniers de sa génération. Déranger avec ceux qui dérangent pour le plus grand plaisir des gourmands, c'est aussi un des travers de GaultMillau. (GM $\mathrm{n}^{\circ}$ 303, Lyon, Notre Clé d'Or; p.30)

É interessante constatar que é através da 'impertinência do talento' desse chef que ousa, 'incomoda', que a qualidade de seu trabalho é ressaltada. Isso se deve ao fato de que tanto o chef Gauvreau quanto o jornalista de GaultMillau funcionam como 'formadores de opinião', o que Ihes permite, segundo Pierre Bourdieu (1979:285), não se submeterem às regras comuns a todos, uma vez que suas transgressões representam o ponto de partida de uma nova moda ou forma de ação/expressão, tendendo a se converter, por sua vez, em uma nova norma.

O enunciador-crítico exerce também sua auto-crítica, colocando-se em questão:

Nous-mêmes avons besoin d'une remise en question: à une vigilance accrue répondront nos encouragements à l'égard de ceux qui maintiendront le cap de la créativité et de la modération dans le prix. (GM ñ302, Le Livre d'Or. du Goût, p.19)

C'est bien injustement que cette maison située sur les hauteurs de Dijon a échappé à notre Guide France 95. Elle tourne en effet plus rond que jamais depuis sa reprise en main par le chef Emmanuel Joinville (...). $\left(\mathrm{GM}^{\circ}\right.$ 304, Tables province, p.19) 
Algumas vezes, o enunciador-critico, fazendo do leitor seu cúmplice, se dirige a seus pares, aqueles que exercem a mesma função, reforçando sua posição de saber:

(...) et vous conviendrez avec nous que les "Elysées du Vernet" tiennent en la personne d'Alain Solivérès - pour peu qu'on lui en donne les moyens - un sérieux candidat au deuxième macaron Michelin. Si ce n'était que de nous, ce serait déjà chose faite! ( $\mathrm{S} \mathrm{n}^{\circ} 44$, Actualités, A Table, p.8)

ou ainda demonstrando que acompanha o trabalho de seus colegas:

Quant au canard laqué, un modèle du genre, après une page entière chez notre confrère Le Monde, il est devenu ici une spécialité incontournable. (GM n ${ }^{\circ} 303$, Tables Paris et Région parisienne, p.106)

Legitimado por sua posição de autoridade, conhecedor de sua área de atuação a ponto de ser convidado a escrever artigos especializados em revistas não menos especializadas, o crítico vai trabalhar no sentido de ampliar junto ao público-leitor sua credibilidades. Para tal, vai sustentar uma imagem que lhe dê um estatuto de 'crítico de arte'. Ao reconhecer e legitimar a gastronomia como arte e o chef como artista-criador, o jornalista se legitima enquanto crítico de arte. Longe de ser um olhar neutro, trata-se de um olhar entre pares que se reconhecem por interagirem no mesmo campo cultural.

Sua credibilidade será tanto mais sólida quanto mais competente for o discurso de convencimento do jornalista que se apresenta como culto e refinado, sensível e inteligente. É preciso ressaltar que essa cultura e inteligência não devem ser expressas num raciocínio lógico elaborado, um simples verniz já basta. Excesso de elaboração

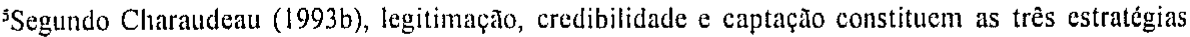
discursivas básicas de que dispỏe o locutor-emissor na produção de seu discurso, com o propósito de obter a adesão do interlocutor-receptor. A primeira se sustenta na adequaçăo da identidade psico-social do sujetto a seu comportamento linguagistico; a segunda procura ajustar o dizer e o lazer, ressaltando a competência do locutor-emissor; e a terceira visa à adesão do interlocutor através da sedução.
} 
poderia significar tédio. Nesse sentido, o jornalista gastronômico se situa na esteira do honnête homme do século XVII.

Cada sociedade, cada civilização constrói uma imagem ideal de homem e o honnête homme corresponde a um ideal de francês, completo e perfeito, que une cultura intelectual, humanística, arte de viver em sociedade, verve (esprit), galanteria, maneiras polidas e bom gosto. Tóda essa cultura, essa distinção, está a serviço da tão prezada arte de conversar e dissertar que se consuma em sociedade, desenvolvendo-se sob o olhar aprovador do outro.

O honnête homme, por sua vez, insere-se na linhagem do cavaleiro medieval que vive circunscrito pelo código moral da nobreza: a cortesia. O cavaleiro, imbuído do mais alto ideal de humanidade, deve possuir e praticar as qualidades físicas, morais e espirituais valorizadas socialmente, sendo corajoso, forte, generoso, belo e elegante. Seu contraponto é o plebeu que, por pertencer à casta inferior, por não ter berço, encarna a condição oposta e os atributos que lhe são correspondentes: é medroso, mesquinho, avaro, feio, fraco e poltrão.

Como salienta o lingüista Pierre Guiraud (1975:14-17), todo o sistema conceitual que fundamenta a noção de polidez, tão capital nos ritos de sociabilidade da Gastronomia, advém da evolução do adjetivo cortês (hoje, sinônimo justamente de polido). Polido e polidez correspondem ao liso e ao bem acabado, representando o ideal de perfeição das relações sociais tanto para o cavaleiro da Idade Média quanto para seu herdeiro, o honnête homme.

Ora, o conceito de belo em francês tem um caráter eminentemente cultural, sendo o resultado de um polimento. Estudando o campo sinonímico dos adjetivos belo e feio nas gírias e no francês popular, Guiraud constata que o campo semântico do belo compreende as noções de bem acabado, per-feito; polido, aplainado, desbastado; mas também de bom e verdadeiro. O objeto perfeito é aquele que foi polido, desbastado, despojado de tudo o que é excessivo, inútil e grosseiro. 
Esse amálgama entre o belo, o bom e o verdadeiro constitui a base das estéticas medieval e clássica. A eles se opõem evidentemente o feio e suas propriedades correlatas: o falso, o ruim, o sujo, o injurioso, o ultrajante. No sistema de valores do campo gastronômico, esse amálgama se encontra igualmente presente, configurando-se num dos pilares de sua ética-estética.

O jornalista gastronômico apresenta-se, pois, como um connaisseur, cuja competência supõe uma aquisição lenta que estabelece pouco a pouco uma familiaridade com a obra gastronômica. Por ser lenta e rara, constitui um objeto de distinção para aquele que a possui. A legitimação e a credibilidade do jornalista se baseiam na sua capacidade de julgar:

(...) o julgamento de gosto é a manifestação suprema do discernimento que, reconciliando o entendimento e a sensibilidade, o pedante que compreende sem sentir e o mundano que goza sem compreender, define o homem realizado. (BOURDIEU, 1979:9)

A captação do leitor se faz através de uma imagem sedutora de crítico amante, aquele que ama incondicionalmente todos os meandros da Arte da Gastronomia bem consumada. No entanto, não se trata da imagem de um amante cego pela paixão ao objeto, mas de alguém de quem a paixão exacerbaria a perspicácia e sensibilidade.

A análise do corpus pesquisado permite concluir que, ao discorrer sobre a arte de comer, o jornalista-gastronômico instaura uma arte de viver à francesa, pois "assim que o alimento é" dito, "ele é, ousamos dizer, "cozido", ou seja, tirado de sua materialidade crua, "natural", para ocupar um lugar numa rede de formas e trocas que marcam sua entrada na cultura". (DADOUN, 1993:58)

A construção da retórica culinário-gastronômica se fundamenta em clichês lexicais que dão forma ao universo discursivo do iulgamento de gosto. Estes respondem à ética culinária francesa contemporânea que repousa, em grande parte, num ideal, cujo desejo de Perfeição busca o amálgama entre o Belo, o Bom e o Verdadeiro. 
O gosto, como conjunto de preferências distintivas, é constituído pelo habitus, esquemas incorporados que sedimentam o modo de olhar e de viver, a ética e a estética da prática burguesa, formando os estilos de vida nos quais se inscreve o campo da gastronomia (BOURDIEU:1979). Nesse campo, todos os sentidos são igualmente valorizados e ativados na experiência estética da degustação, contrariamente a uma vasta tradição estético-filosófica, na qual o primado artístico era dado unicamente à visão e à audição. Como enfatiza o filósofo Michel Serres (1985:167), o que instaura o homo sapiens é antes de tudo o paladar. O gosto, como construção da inteligência, lhe é posterior; a sapiência e a sagacidade advindo da degustação.

Nunca é demais lembrar que a cozinha de papel é uma cozinha discursiva. "O enunciado gastronômico, por mobilizar um desejo aparentemente simples, apresenta em toda a sua ambigüidade o poder da linguagem: o signo chama as delícias de seu referente no instante exato em que traça sua ausência (...)" (BARTHES, 1975:289). O signo gastronômico é, assim, a marca de uma ausência, aquilo que se dá a ver, a sentir e a conhecer, como algo a ser visualizado, em todas as gamas de detalhes, para ser desejado. Muito mais do que alimentar o corpo, busca-se alimentar a imaginação e o sonho.

A cozinha de papel, além de informar, deve seduzir através de uma argumentação e uma descrição que incitem a transformar a imaginação do leitor em palco, onde se desenrola o Acontecimento Gastronômico, despertando emoções e desejos com seus aromas e sabores. Trata-se de tarefa não menos árdua do que fazer o leitor degustar, e sobretudo, fazê-lo viajar sem sair da poltrona. Ou ainda, para os mais abastados, incitar a consumir no restaurante a obra gastronômica do chef.

\section{Referências Bibliográficas}

BARTHES, Roland. Lecture de Brillat-Savarin (1975). Oeuvres Complètes. Tome III.1974-1980. Paris:Seuil, 1995. 
BOURDIEU, Pierre. La Distinction. Critique sociale du jugement. Paris: Minuit, 1979.

BRILLAT-SAVARIN, Jean-Anthelme. Physiologie du goût. Paris: Julliard, 1965.

CHARAUDEAU, Patrick. La Critique Cinématographique: Faire Voir et Faire Parler. La Presse. Produit, Production, Réception. Paris: Didier Érudition, 1988.

- Grammaire du Sens et de l'Expression. Paris: Hachette, 1992.

- Catégories de Langue, Catégories de Discours et Contrat de Communication. Parcours linguistiques de discours spécialisés. Berne: Peter Lang, 1993a.

_. Des conditions de la "mise en scène" du langage in. L'esprit de société vers une anthropologie sociale du sens (sous la direction de Anne Decrosse). Bruxelles: Mardaga, 1993.

- Le Contrat de Communication de l'Information Médiatique. Le Français dans le Monde, numéro spécial, Recherches et Applications. Médias - Faits et Effets. Paris: Hachette, juillet 1994.

DADOUN, Roger. La bouche d'Éros. La Gourmandise. Délices d'un péché. Revue Mangeurs, ${ }^{\circ} 140$. Paris: Autrement, 1993.

GUIRAUD, Pierre. Les Grots Mots. Paris: PUF, 1975. (Coll. "Que sais-je?”)

SERRES, Michel. Les cinq sens. Philosophie des corps mêlés-1. Paris: Bernard Grasset, 1985.

RÉSUMÉ: Ce travail propose une analyse du jugement de goût et des images du journaliste gastronomique, présentes dans les revues Saveurs, Cuisine et Vins de France, La Bonne Cuisine et GaultMillau, à partir de la théorie sémiolinguistique du discours de Patrick Charaudeau et des concepts sociologigues de Pierre Bourdieu. 